\title{
Cost-effective payments for reducing emissions from deforestation under uncertainty
}

Stefanie Engel, Charles Palmer, Luca Taschini and Simon Urech

February 2012

Centre for Climate Change Economics and Policy Working Paper No. 82

Grantham Research Institute on Climate Change and the Environment Working Paper No. 72 
The Centre for Climate Change Economics and Policy (CCCEP) was established by the University of Leeds and the London School of Economics and Political Science in 2008 to advance public and private action on climate change through innovative, rigorous research. The Centre is funded by the UK Economic and Social Research Council and has five inter-linked research programmes:

1. Developing climate science and economics

2. Climate change governance for a new global deal

3. Adaptation to climate change and human development

4. Governments, markets and climate change mitigation

5. The Munich Re Programme - Evaluating the economics of climate risks and opportunities in the insurance sector

More information about the Centre for Climate Change Economics and Policy can be found at: http://www.cccep.ac.uk.

The Grantham Research Institute on Climate Change and the Environment was established by the London School of Economics and Political Science in 2008 to bring together international expertise on economics, finance, geography, the environment, international development and political economy to create a worldleading centre for policy-relevant research and training in climate change and the environment. The Institute is funded by the Grantham Foundation for the Protection of the Environment, and has five research programmes:

1. Use of climate science in decision-making

2. Mitigation of climate change (including the roles of carbon markets and lowcarbon technologies)

3. Impacts of, and adaptation to, climate change, and its effects on development

4. Governance of climate change

5. Management of forests and ecosystems

More information about the Grantham Research Institute on Climate Change and the Environment can be found at: http://www.Ise.ac.uk/grantham.

This working paper is intended to stimulate discussion within the research community and among users of research, and its content may have been submitted for publication in academic journals. It has been reviewed by at least one internal referee before publication. The views expressed in this paper represent those of the author(s) and do not necessarily represent those of the host institutions or funders. 


\title{
Cost-Effective Payments for Reducing Emissions from Deforestation Under Uncertainty*
}

\author{
Stefanie Engel ${ }^{\dagger} \quad$ Charles Palmer $^{\ddagger} \quad$ Luca Taschini ${ }^{\S}$ \\ Simon Urech
}

January 13, 2012

\begin{abstract}
The paper analyses the implications of landowners' option values in land allocation and derives policy recommendations for payments for Reducing Emissions from Deforestation and Forest Degradation (REDD). Given that REDD will not represent a permanent change in the cumulative flux of carbon dioxide to the atmosphere, payment scheme design is motivated by the need to secure forest carbon sinks over time (the 'permanence criterion') while remaining relatively cost-effective. Alternative payment schemes, combining fixed and variable components, are considered in a framework with two competing land uses, forest and agriculture. Cost-effectiveness depends on the dependency structure between the returns from the indexed component of the payment and the returns from the alternative land use, the relative volatility level of the underlying returns, and the relative combination of fixed and variable payments. After developing the general model, it is is applied to REDD policy scenarios in Parana State, Brazil.
\end{abstract}

Keywords: Deforestation; Land use change; Payments; Permanence; Uncertainty. JEL Classifications: Q23; Q28; Q15.

*We thank André Albuquerque Sant'Anna, Alex Marten, Michael Cordonnier, Sam Fankhauser, and session participants at the Fourth World Congress of Environmental and Resource Economists in Montreal, at the Climate Economics and Law Workshop in Bern, and at the 13th Annual BIOECON Conference in Geneva for their valuable comments and discussions. Many thanks also to Saraly Andrade de Sa and Markus Ohndorf for commenting on an earlier draft of this paper. Stefanie Engel and Simon Urech thank the CCES project ClimPol (Climate Policy Making for Enhanced Technological and Institutional Innovations) for funding this research. Luca Taschini gratefully acknowledges financial support from the Grantham Research Institute on Climate Change and the Environment and the Economic and Social Research Council, UK. The usual disclaimers apply.

$\dagger$ Address: Environmental Policy and Economics PEPE, ETH Zurich, Switzerland. E-mail: stefanie.engel@env.ethz.ch

$\ddagger$ Address: Department of Geography and Environment, London School of Economics and Political Science, UK. E-mail: c.palmer1@lse.ac.uk

$\S$ Address: The Grantham Research Institute on Climate Change and the Environment, the London School of Economics and Political Science, UK. E-mail: l.taschini1@lse.ac.uk

"Address: Environmental Policy and Economics PEPE, ETH Zurich, Switzerland. E-mail: surech@ethz.ch 


\section{Introduction}

With tropical deforestation accounting for up to a fifth of global, anthropogenic $\mathrm{CO}_{2}$ emissions (van der Werf et al. (2009)), Reducing Emissions from Deforestation and Degradation (hereafter 'REDD') has been posited as a cost-effective climate change mitigation strategy (Stern (2007); Eliasch (2008); Palmer and Engel (2009)). ${ }^{1}$ Policy options for REDD span the range of well-known interventions in forest and land use, although incentive payments or payments for environmental services (PES) are often emphasised (Angelsen (2010); Palmer (2011)). A major selling point of PES is their relative, potential cost-effectiveness compared to other policy options (Ferraro and Kiss (2002); Ferraro and Simpson (2002); Muller and Albers (2004); Groom and Palmer (2010)). For REDD, the challenge is to design costeffective payments that can secure forest climate services in settings where the returns from different land uses constantly change. Stochastic control models, which have long been applied to forest management problems, are of particular relevance for this policy setting. In these, the incentives driving land-use change under uncertainty are central. Of particular interest are those that enable a land-use change from forest to agriculture and vice versa (e.g. Bulte et al. (2002); Schatzki (2003); Isik and Yang (2004); Wiemers and Behan (2004); Behan et al. (2006)). Yet, previous work neither considered the cost-effectiveness of different payment schemes under uncertainty nor has there been an explicit focus on REDD.

This paper proposes an index-based REDD payment scheme that meets a pre-set probabilistic criterion to keep land in forest. We investigate its cost-effectiveness using a model of land-use change, which is characterized by dependent and stochastic alternative land-use returns. A key innovation of our paper is the development of a criterion to keep land in forest, which we term the 'permanence' criterion. Since carbon sequestered in the terrestrial biosphere is not permanently removed from the atmosphere, it is at constant risk of being returned through deforestation whether intentional or not. Thus, REDD will not represent a permanent change in the cumulative flux of carbon dioxide to the atmosphere and perfect permanence will always be impossible to attain. ${ }^{2}$

\footnotetext{
1'REDD+' encompasses policies and activities to prevent or slow deforestation and degradation, and increase forest carbon stocks. It has been considered for inclusion in a post-2012 global climate regime (UNFCCC (2010)). In this paper we mainly focus on the cost-effectiveness of REDD and not REDD+. We also assume throughout that REDD is socially optimal. Previous research has shown that it is often less expensive than alternative mitigation options and has high side benefits, e.g. biodiversity (see Palmer and Engel (2009)).

${ }^{2}$ While this also applies to industrial emissions sources, we adopt the viewpoint of Watson et al. (2000)
} 
There are several types of risks that jeopardize permanence in forest carbon sinks. ${ }^{3}$ We focus on demand-side risk in the presence of stochastic returns. This is the risk that an increase in profits from the alternative land use raises landowner's opportunity costs of keeping land under the original use above the value of the REDD payment. In this case, it might become profitable for landowners to change land use. Understanding how these risks affect landowners' decisions can provide valuable insights for the design of payment schemes that ensure permanence. With recent booms in commodities' prices - including in agriculture - there is an increasing need to design payments schemes that can adapt to impending population increases and rising food- and energy-related demands for land. While we believe our results are of general relevance for PES design, we focus our analysis on forest carbon and REDD payments. Stakeholders with billions of dollars invested in REDD fear that reductions in loss of forest carbon stocks may be credited now or rewarded across time but that these stocks may later disappear due to opportunistic land conversion. ${ }^{4}$

Beginning with the Stern Review (2006), the decision to allocate land use between forestry and an alternative in the REDD literature has generally been tackled employing standard discounted cash flow techniques (e.g. Nepstad et al. (2007); Boerner and Wunder (2008); Butler et al. (2009)). Closer scrutiny of the data used in the Stern Review suggests wide variation in the opportunity costs of keeping land in forest over a 30 year period using a 10 percent discount rate, even within countries. For example, including the returns from a one-off timber harvest, opportunity costs in Brazil range from around US $\$ 600$ per hectare for large-scale cattle ranching to US\$2,100 per hectare for soybean production (see Grieg-Gran (2009)). The main assumption of these kinds of analyses is that future opportunity costs are known with certainty and hence, these studies are limited in guiding policy design with respect to demand-side risk.

Dutschke and Angelsen (2008) were the first to explore possible REDD policy options regarding permanence. To manage demand-side risk one suggestion is to index REDD transfers to a relevant agricultural commodity index if prices move out of a 'pre-determined

that reductions in fossil fuel emissions can be regarded as leading to more permanent reductions in cumulative flows to the atmosphere in contrast to reductions in deforestation.

${ }^{3}$ Dutschke and Wong (2003) discusses the potential difficulties of addressing permanence in the presence of different types of risk. Note that the term permanence has a looser definition in this paper than that commonly used in the REDD+ literature. Under a national approach to reducing emissions, for example, the concern is less about permanence of specific forest areas but instead whether a particular country continues to maintain changes in emissions below some reference level (Dutschke and Angelsen (2008)).

${ }^{4}$ Along with possible REDD contract breach by landowners (see MacKenzie et al. (2011)). While credit buffers, risk pools and insurance allow for some mitigation of risk, these provide only limited incentives to ensuring permanence at the landowner level. 
price corridor'. Otherwise, such transfers would remain fixed as is commonly observed in PES schemes around the world (Engel et al. (2008)). However, this idea was not explored in any further detail. Indexing payments to landowners' agricultural incomes was considered by Benítez et al. (2006), who extended the use of stochastic dominance rules to conservation payments needed to prevent land-use change. In bearing part of the landowner's income risk, the conservation buyer can benefit from lower total conservation costs if these risks are spread across many landowners and over time. Benítez et al. (2006) also discuss the role of irreversibility in land-use decisions and admit that by ignoring this, their estimates of the required payment levels may be too high.

The land-use allocation problem for REDD involves sunk costs and uncertain profits. Studying the land conversion problem from forestry to agriculture, Schatzki (2003) shows that it is optimal for land owners to delay land-use change when conversion costs are sunk and the returns from alternative land uses are uncertain. This is a standard result in real options theory and accounts for the idea that land use can be considered as a real asset with an attached perpetual option to convert it to another land use at any time. ${ }^{5}$ Depending on the levels of uncertainty that characterize the problem, these option values to delay are potentially large. Incorporating these in payments for forest conservation may lower payment values. Guthrie and Kumareswaran (2009) consider the effect of carbon credit payments on forest owners' land use and harvest decisions using a real options model. Payments are either paid on the basis of the amount of carbon sequestered at a given point in time or a payment paid on the basis of the long-run carbon sequestration potential of the land. They find that the former scheme leads to greater carbon sequestration at a lower cost than the latter. While the timber price, i.e. landowner's opportunity cost, is modeled as a source of volatility, carbon prices are not modeled stochastically. In our model, neither the landowner's opportunity cost of keeping land in forest nor the value of the indexed payments is known with certainty. Yet, if both returns are stochastic then from a REDD policy perspective there is a need to better understand the dependency structure between these two.

We first develop a general model of optimal land-use change under stochastic returns with two land uses, forest and agriculture. A risk-neutral land owner decides whether to retain her starting-point land use, whether forest or agriculture, or to change to the

\footnotetext{
${ }^{5}$ We refer to McDonald and Siegel (1986) and Pindyck (1988) for an introductory discussion about options theory applied to real investments. A more comprehensive description of the real options theory can be found in Dixit and Pindyck (1994), Dixit (1989), and Pindyck (1991).
} 
alternative. We then focus on the decision of whether to keep land in forest with REDD payments or to convert the forest to agriculture. The payment scheme comprises both constant and indexed payment components. Building on standard concepts of financial risk management, we impose our permanence criterion on this decision. Thus, for a given unit of land, probability and time horizon, we identify combinations of the parameters of the payment scheme that ensure the landowner keeps her land in forest with a probability not lower than 90 percent.

In Section 2, we show that the relative cost-effectiveness of different payment schemes depends on three features of the scheme under consideration. First, the dependency structure between the returns from the indexed component of the payment and the returns from the alternative land use. This has not been considered in the literature before. Our results suggest that the more correlated these two returns the lower the cost of the policy overall. Second, the relative volatility level of the underlying returns. Here, we reproduce standard real option results in that the greater the volatility of payments the higher the upside potential profits. This makes the option value to delay land-use change, i.e. no land conversion, more appreciable. Third, the relative combination of fixed and variable payment components. A higher option value to delay allows for a reduction in the fixed component of the payment and, ultimately, reduces policy costs.

The model is then applied to policy scenarios in Section 3, specifically to the design of cost-effective payments made to landowners in Parana State, Brazil. In becoming one of Brazil's major soybean producing regions, Parana has experienced high rates of forest loss (see Fearnside (2001); Angelsen and Kaimowitz (2001)). With potential for further high returns on agriculture, the area could continue to be at high risk of severe deforestation. In other words, Parana is a prime candidate for REDD payments to slow deforestation. Indeed, Brazil is an active participant in REDD policy debates at the international level.

After calibrating the dynamics of alternative land-use returns to Parana's soy bean index, we estimate the dynamics of forest-related returns, i.e. the REDD payments, with respect to two observable price indices: the CBOT (Chicago Board of Trade) Soybean May Futures and the European Union's Emissions Trading System permit price. Thus, motivated by the work of Dutschke and Angelsen (2008) and Benítez et al. (2006), we first link the variable payment component to an agricultural commodity index that correlates with landowners' opportunity costs. We then consider linking this component to carbon prices. While not a feature of the Kyoto architecture, linking payments in the Clean Development Mechanism to the secondary market price of permits has been discussed 
in the literature, e.g. (Mehta and Capoor (2003), Streck (2005)), and was considered in previous meetings of the United Nations Framework Convention on Climate Change. Linking future REDD payments to carbon market prices, however, remains a possibility in the event of market integration (Gregersen et al. (2010)). ${ }^{6}$ The costs of payment schemes with indexed components based on one of these indices are compared. Consistent with the results presented in Section 2, our findings illustrate the costs of securing permanence in a high-risk area through the indexing of payments to landowners. These results, along with their policy implications and limitations, are discussed in Section 4.

\section{The model}

In this paper we value a representative single-hectare of land that generates profits from one of two alternative uses: forest (hereafter $F$ ) or agriculture (hereafter $A$ ). Whenever the land use is changed, conversion costs are incurred. Costs for changing from forest to agriculture, $\left(C C_{F A}\right)$ and, vice versa, from agriculture to forest, $\left(C C_{A F}\right)$ are sunk. ${ }^{7}$ Profits to the landowner from forest are generated by an incentive payment program while profits from agriculture are generated by crop sales. Future returns both from forest and agriculture are, in principle, uncertain.

\subsection{Payment program and the landowner's decision}

We consider a payment program with two components: (i) a constant per-hectare payment, $c$; and, (ii) a per-hectare indexed payment component, $I$, scaled by a pre-set coefficient, $\alpha$. The second component $I$, can correspond to some observable price index, the return process of which may be dependent or independent with respect to alternative agricultural returns. Forest returns correspond to the sum of these two components, i.e. $F=c+\alpha \cdot I$. Our aim is to identify a pair $(c, \alpha)$ that makes profitable the carbon dioxide sequestration service of forest for a given time horizon, $T$. Later, in Section 2.2, we spell out the probabilistic rule we propose to assess how likely the land is kept in forest, i.e. the permanence criterion. Then,

\footnotetext{
${ }^{6}$ In the voluntary markets, sales of Verified Emissions Reductions finance payments that incentivize shifts in local land use towards ones supplying higher carbon benefits, e.g. agroforestry and reforestation activities by local farmers in Mozambique (Palmer and Silber (2012)).

${ }^{7}$ Later, when introducing the probabilistic permanence criterion, we concentrate on the situation where the land use is changed from forest to agriculture and neglect a possible change back from agriculture to forest. The model can easily accommodate this by imposing very high conversion costs, $\left(C C_{A F}\right)$, that preclude such an event.
} 
in Section 2.3, we quantify the relative cost-effectiveness of different payment programs that meet such a criterion. We first introduce the general model of land-use change. Assume that the index returns process $I$ evolves according to the following stochastic process:

$$
d I=\mu_{I} I d t+\sigma_{I} I d W_{I}
$$

where $\mu_{I}$ is the constant drift term, $\sigma_{I}$ is a positive constant, and $W_{I}$ is assumed to be standard normally distributed. Similarly, we assume the agricultural return process $A$ evolves according to a second stochastic process:

$$
d A=\mu_{A} A d t+\sigma_{A} A d W_{A}
$$

where $\mu_{A}$ is the constant drift term, and $\sigma_{A}$ is again a positive constant. Because the two return processes may be correlated, we introduce a second process $W_{a}$ that is assumed to be standard normally distributed, and such that $W_{A}=\rho_{I A} \cdot W_{I}+\sqrt{1-\rho_{I A}^{2}} \cdot W_{a}$, and $\rho_{I A}$ represents the unconditional correlation. Note that we model the returns directly instead of modelling the price and crop yield uncertainties separately. This simplifies our analysis considerably and allows us to utilize existing numerical techniques to solve the optimal land-conversion problem. In Section 3, we parametrize the return processes to observable price indices, yield processes, conversion costs and payment programs. All these values are specified per hectare of land. In the following sections we concentrate on those policies where the forest returns are indexed to some return value that is, to varying degrees, correlated with the returns from the alternative land use.

Over each increment of time $d t$, a landowner receives $F d t$ if the land is in forest or $A d t$ if the land is in agriculture. Assume first a starting point of land in forest. At each point in time, the landowner decides either to keep her land in forest or to convert the forest to agriculture. The decision to change land use generates instantaneous profits net of conversion costs. Alternatively, the landowner can delay the decision to harvest the forest and continue to receive the forest returns, i.e. the payments. Thus, the value of a single hectare of forest is

$$
f(F, A, t)=\max \left\{\pi^{F}, \pi^{A}-C C_{F A}\right\}
$$

The first term on the right-hand side describes the returns if the land is kept in forest. The landowner receives a payment of $F d t$ and the discounted future expected returns from the 
land. Therefore, $\pi^{F}$ represents the landowner's return from forest use. In particular

$$
\pi^{F}=F d t+e^{-r d t} \mathbb{E}[f(F+d F, A+d A, t+d t)]
$$

where $\mathbb{E}$ is the expectation operator. All returns are valued by discounting their expected values at the constant, continuously compounded, risk-free discount rate $r$. The second term of Equation (3) is the return when the land is converted from forest to agriculture. The landowner incurs sunk conversion costs equal to $C C_{F A}{ }^{8}$

For generality, we also explore the possibility of converting from agriculture to forest, i.e. via activities that increase forest carbon stocks. This is not only relevant for REDD+ as defined in footnote (1) but also for afforestation or reforestation activities undertaken in the Clean Development Mechanism (CDM) of the Kyoto Protocol. When the initial land use is agriculture, the landowner faces a similar decision-making problem. She can either produce the agricultural commodity before converting the land to forest, or postpone this decision and continue with agricultural production. Therefore, the value of a single hectare of agriculture is

$$
g(F, A, t)=\max \left\{\pi^{A}, \pi^{F}-C C_{A F}\right\} .
$$

Similar to the previous situation, the first term on the right-hand side describes the returns if the land is kept in agriculture. The landowner receives a profit $A d t$ from agriculture and the discounted future expected returns of land:

$$
\pi^{A}=A d t+e^{-r d t} \mathbb{E}[g(F+d F, A+d A, t+d t)]
$$

If the landowner decides to change her land-use from agriculture to forest she faces conversion costs equal to $C C_{A F}$.

For $\pi^{F}$ and using Ito's Lemma, we obtain:

$$
\begin{aligned}
\pi^{F} & =f(F, A, t) \\
& +\left(\frac{\partial f}{\partial t}+\frac{1}{2} \sigma_{F}^{2} F^{2} \frac{\partial^{2} f}{\partial F^{2}}+\mu_{F} F \frac{\partial f}{\partial F}+\frac{1}{2} \sigma_{A}^{2} A^{2} \frac{\partial^{2} f}{\partial A^{2}}+\mu_{A} A \frac{\partial f}{\partial A}-\rho_{F A} \sigma_{F} \sigma_{A} \frac{\partial f}{\partial F \partial A}-r f\right) d t \\
& +F d t .
\end{aligned}
$$

\footnotetext{
${ }^{8}$ Conversion from forest to agriculture may also generate a one-time timber profit. Such extra profit may be explicitly accounted for by modeling the timber price, the volume of timber extracted from the forest, and the harvest costs. For model tractability, we do not explicitly model these profits. In Section 3 , however, we incorporate a one-off timber profit amounting to 30 percent of the conversion costs, $C C_{F A}$.
} 
Similarly, for $\pi^{A}$ we obtain:

$$
\begin{aligned}
\pi^{A} & =g(F, A, t) \\
& +\left(\frac{\partial g}{\partial t}+\frac{1}{2} \sigma_{A}^{2} A^{2} \frac{\partial^{2} g}{\partial A^{2}}+\mu_{A} A \frac{\partial g}{\partial A}+\frac{1}{2} \sigma_{F}^{2} F^{2} \frac{\partial^{2} g}{\partial F^{2}}+\mu_{F} F \frac{\partial g}{\partial F}-\rho_{F A} \sigma_{F} \sigma_{A} \frac{\partial g}{\partial F \partial A}-r g\right) d t \\
& + \text { Adt }
\end{aligned}
$$

We know from Equation (3) that $f(F, A, t)$ must be at least as large as $\pi^{F}$ or $\pi^{A}-C C_{F A}$. That is, $f(F, A, t)$ must satisfy:

$$
0 \geq \frac{\partial f}{\partial t}+\frac{1}{2} \sigma_{F}^{2} F \frac{\partial^{2} f}{\partial F^{2}}+\mu_{F} F \frac{\partial f}{\partial F}+\frac{1}{2} \sigma_{A}^{2} A \frac{\partial^{2} f}{\partial A^{2}}+\mu_{A} A \frac{\partial f}{\partial A}-\rho_{F A} \sigma_{F} \sigma_{A} \frac{\partial f}{\partial F \partial A}-r f+F,
$$

$$
f(F, A, t) \geq \pi^{A}-C C_{F A}
$$

We also know from Equation (5) that $g(F, A, t)$ must be at least as large as $\pi^{A}$ and $\pi^{F}-C C_{A F}$. Therefore, $g(F, A, t)$ must satisfy:

$$
\begin{gathered}
0 \geq \frac{\partial g}{\partial t}+\frac{1}{2} \sigma_{A}^{2} A \frac{\partial^{2} g}{\partial A^{2}}+\mu_{A} A \frac{\partial g}{\partial A}+\frac{1}{2} \sigma_{F}^{2} F \frac{\partial^{2} g}{\partial F^{2}}+\mu_{F} F \frac{\partial g}{\partial F}-\rho_{F A} \sigma_{F} \sigma_{A} \frac{\partial g}{\partial F \partial A}-r g+A, \\
g(F, A, t) \geq \pi^{F}-C C_{A F} .
\end{gathered}
$$

At least one of the two conditions for $f(\cdot)$ and $g(\cdot)$ must hold with equality. For example, for land in forest, if Equation (9) is an equality, then the landowner should keep her land in forest. Conversely, if Equation (10) is an equality, the landowner should change her land use to agriculture. For land in agriculture, if Equation (11) is an equality, then the landowner should keep her land in agriculture. Conversely, if Equation (12) is an equality, the landowner should change her land use to forest. In all other cases, the landowner is indifferent between converting and not converting, i.e. it is optimal to wait. Because the two value functions $f(F, A, t)$ and $g(F, A, t)$ are interdependent, there are no analytical solutions to the system of the Equations (9) and (10) and (11) and (12). Therefore, we solve the optimal land-use change problem numerically. ${ }^{9}$

\footnotetext{
${ }^{9}$ We solve this problem using the collocation method. This approach approximates the unknown value functions $f(F, A, t)$ and $g(F, A, t)$ using linear combination of $n$ known basis functions. We refer to Miranda and Fackler (2002) and Dangl and Wirl (2004) for a comprehensive explanation. Often, the finite
} 
To solve the land-use change problem we first evaluate the optimal conversion boundaries given the parameters of the forest $F_{t}$ and the agriculture returns $A_{t}$, respectively; the conversion costs $C C_{F A}$ and $C C_{A F}$; the dependence structure between the two alternative land uses, forest and agriculture, $\rho_{I A}$; and the discount rate $r$. Figure 1 represents the conversion boundaries given a possible set of parameters chosen. In particular, the solid line corresponds to the boundary for the conversion from forest to agriculture, $C_{F A}$; the dashed line corresponds to the boundary for the conversion from agriculture to forest, $C_{A F}$. Supposing the land is in forest, when a simulated forest return turns out to be below the boundary from forest to agriculture $\left(C_{F A}\right)$, the landowner changes from forest to agriculture. Conversely, she keeps the land in forest. Supposing the land is in agriculture, when a simulated agriculture return turns out to be above the boundary from agriculture to forest $\left(C_{A F}\right)$, the landowner changes. Conversely, she keeps the land in agriculture. The area between the two boundaries is the waiting region.

\subsection{Probabilistic permanence criterion}

The general model shows when it is optimal to change land from one use to another, and vice versa. To be of relevance to the policy discussion on REDD, we now focus on the incentives required to prevent a change from forest to agriculture, i.e. such that the landowner continues to postpone the decision to change from forest to agriculture.

Once the underlying, observable index market $I$ is chosen, a specific criteria is required to identify the $(c, \alpha)$ pair, i.e. respectively, the constant per-hectare payment component and the scaling coefficient for the variable payment component, that ensures land is kept in forest. Building on standard concepts of financial risk management, we propose a probabilistic permanence criterion. For a given hectare of forestland, a pre-set probability level, $p$, and a chosen time horizon, $T$, the pair $(c, \alpha)$ is derived to ensure that the land remains in forest over the given time horizon with a probability not lower than the specified probability level. Together $p$ and $T$ identify the permanence criterion. Note that since $p$ can be interpreted as the probability of avoiding deforestation, $(1-p)$ corresponds to the probability of deforestation.

In order to determine the pair $(c, \alpha)$ that satisfies the permanence criterion, we first evaluate the optimal conversion boundaries given a specific set of model parameters. We

difference method is used to solve numerically the value functions in the framework of stochastic dynamic optimization. However, the collocation method result has proven to be both a quicker and more robust alternative. 


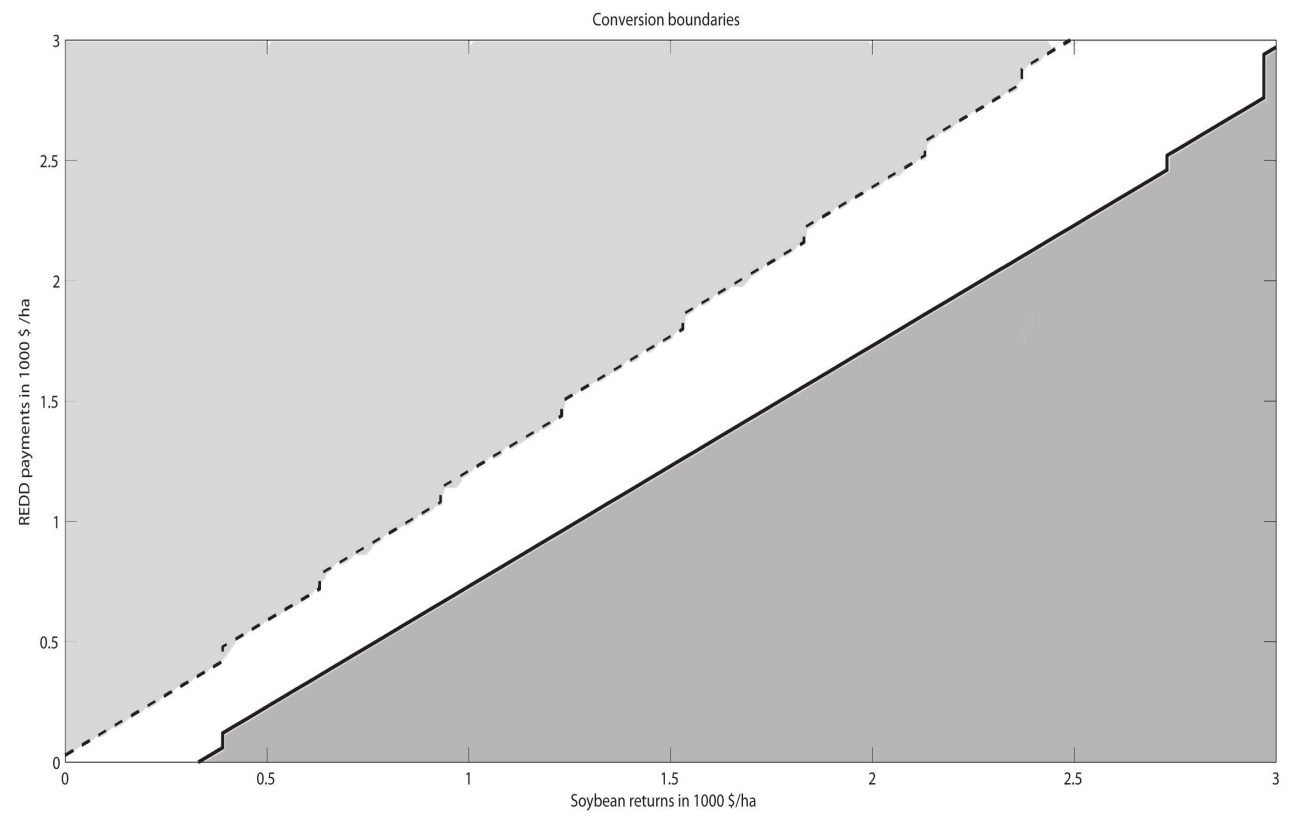

Figure 1: Optimal land-use change and waiting regions. The dashed line corresponds to the boundary for the conversion from forest to agriculture, $C_{A F}$. The solid line corresponds to the boundary for the conversion from agriculture to forest, $C_{F A}$. Within the top light-grey region it is optimal to change land use from agriculture to forest; within the bottom dark-grey region it is optimal to change land use from forest to agriculture. In the clear regions it is optimal to wait.

then solve for the optimal land-use change numerically. Focusing on the starting point of land in forest, we choose different sets of $(c, \alpha)$ and simulate the returns from forest and agriculture. When forest returns are below the conversion boundary $C_{F A}$, changing land use from forest to agriculture is optimal. This comparison is assessed every $s$ months. More specifically, the simulation yields a converted path when agriculture becomes more profitable than forest at any given comparison node, i.e. we assume irreversible conversion at the first node agriculture is more profitable than keeping land in forest. Dividing the total number of non-converted paths by the number of simulations, $S$, we compute the likelihood of a land-use change from forest to agriculture not occurring, $\hat{p}$. A policy meets the permanence criterion when $\hat{p} \geq p$.

\subsection{Model results}

In this sub-section, we explore the relative cost-effectiveness of different payment schemes that ensure the land stays in forest with a probability $p$ of 90 percent over a time period 
$T$ of 30 years. ${ }^{10}$ We elicit combinations of the size of the constant per-hectare component $c$ of the payment scheme along with that of the variable, indexed component $\alpha$ for the least expensive overall payment. Thus, the objective of the carbon service buyer is to determine the pair $(c, \alpha)$ that satisfies the permanence criterion at lowest cost. Achieving policy cost-effectiveness while avoiding deforestation and hence, ensuring the environmental effectiveness of the programme first requires that we compare the two alternative returns to the landowner: agricultural profits on one hand and those coming from the buyer's REDD payments on the other. A number of policy insights follow, particularly with respect to indexing payments to the landowner's opportunity cost of keeping the land in forest, i.e. the alternative land-use returns.

We solve the optimal land-use change problem using a set of parameters that are derived from data used for the real-world policy scenarios in Section 3. Specifically, the initial value of both returns is set equal to the unconditional mean of the log return from a Brazilian soybean index. ${ }^{11}$ Also, conversion costs are based on calculations in the following section. We return to this index and the construction of conversion costs when we explicitly model a Brazilian landowner's alternative returns for the policy scenarios in Section 3. Finally, we use a standard discount factor equal to $5 \%$. All parameters used in this section are reported in Table 1.

Three different scenarios are considered for the dependency structure between the two competing land returns: a high correlation factor of 0.9 , a relatively lower correlation factor of 0.5, and uncorrelated. Given the model parameters and the structure of dependence between returns, we identify the combination of $(c, \alpha)$ that satisfies the permanence criterion. The expected policy cost, i.e. the cost of the pair $(c, \alpha)$, is the average cost accruing from the corresponding non-converted paths. ${ }^{12}$ Table 2 shows that the dependency structure between the indexed returns and the returns from the alternative land uses matters. In particular, relative cost-effectiveness depends upon the correlation factor. The more corre-

\footnotetext{
${ }^{10} \mathrm{CDM}$ guidelines propose that Land Use, Land Use Change and Forestry projects have a duration of between 20 and 60 years. We chose 30 years on the basis of this being the shortest desirable timeframe for securing forest climate benefits from REDD, i.e. in bridging the time to a less carbon-intensive global economy (see Lecocq and Chomitz (2001)). Moreover, policy designed to secure permanence may not even be necessary in 30 years time if there are fewer incentives in the future to deforest the areas protected or afforested today (Chomitz and Thomas (2001)).

${ }^{11}$ If $p_{t-1}$ and $p_{t}$ are two consecutive observations for a price series, the log return $r(t)$ is defined as the difference $\ln \left(p_{t}\right)-\ln \left(p_{t-1}\right)$.

${ }^{12}$ In other words, $E\left[\int_{0}^{T} F(t) d t\right] \approx \sum_{i=1}^{S}\left[\int_{0}^{T} F_{i}(t) d t\right] / S$ where $i$ is the $i$-th simulation that yields to a non-converted land use at each comparison node.
} 


\begin{tabular}{ccc}
\hline Description & Parameter & Value \\
\hline Drift of the index returns & $\mu_{I}$ & 0 \\
Drift of the alternative returns & $\mu_{A}$ & 0 \\
Volatility of the index returns & $\sigma_{I}$ & 0.010 \\
Volatility of the alternative returns & $\sigma_{A}$ & 0.015 \\
Initial value of the index returns/ha & $I_{0}$ & 48.60 \\
Initial value of alternative returns/ha & $A_{0}$ & 48.60 \\
\hline Conversion costs/ha & $C C_{F A}$ & 60.7 \\
Discount rate & $r$ & 0.05 \\
Total length in years & $T$ & 30 \\
Evaluation window in months & $s$ & 6 \\
Number of simulations & $S$ & 10,000 \\
Per-set probability level & $p$ & 0.90 \\
\hline
\end{tabular}

Table 1: Model parameters used in this Section. The unit for the conversion costs and the return processes is $\$ / h a$.

lated the two returns, the lower the cost of the policy. Intuitively, the higher the potential returns coming from agriculture the higher the opportunity cost to keep land in forest. This opportunity-cost wedge, however, may be reduced when the forest returns are indexed to some return value that is highly correlated to the returns from the alternative land use.

The volatility of the underlying returns affects the opportunity-cost wedge in a similar fashion. Suppose the volatility of the index-based forest returns increases from $\sigma_{I}=0.01$ (Scenario 1, in Table 2) to $\sigma_{I}=0.025$ (Scenario 2). Consistent with the real options literature, a more variable payment increases the upside potential profits and, therefore, reduces the opportunity cost of keeping land in forest. As shown in the table, for a given value of $\alpha$, the value of the option to postpone land-use change ultimately makes the policy relatively cheaper because it reduces the fixed payment $c$.

Finally, note that all previous results hold (with reverse sign) when the two alternative land uses are negatively correlated. Testing a policy in which the variable component is indexed to an underlying return that is negatively correlated has, however, no economic meaning. 


\begin{tabular}{|c|c|c|c|c|c|c|}
\hline \multicolumn{7}{|c|}{$\rho=0.9$} \\
\hline \multirow[t]{2}{*}{ Scenario } & \multicolumn{2}{|c|}{$\alpha=0.7$} & \multicolumn{2}{|c|}{$\alpha=0.8$} & \multicolumn{2}{|c|}{$\alpha=0.9$} \\
\hline & $c$ & Cost & $c$ & Cost & $c$ & Cost \\
\hline Scenario 1 & 0.29 & 2,492 & 0.17 & 2,494 & 0.05 & 2,495 \\
\hline Scenario 2 & 0.28 & 2,414 & 0.16 & 2,423 & 0.05 & 2,479 \\
\hline \multicolumn{7}{|c|}{$\rho=0.5$} \\
\hline \multirow[t]{2}{*}{ Scenario } & \multicolumn{2}{|c|}{$\alpha=0.7$} & \multicolumn{2}{|c|}{$\alpha=0.8$} & \multicolumn{2}{|c|}{$\alpha=0.9$} \\
\hline & $c$ & Cost & $c$ & Cost & $c$ & Cost \\
\hline Scenario 1 & 0.30 & 2,502 & 0.17 & 2,503 & 0.06 & 2,537 \\
\hline Scenario 2 & 0.28 & 2,430 & 0.16 & 2,490 & 0.06 & 2,513 \\
\hline \multicolumn{7}{|c|}{$\rho=0.0$} \\
\hline \multirow[t]{2}{*}{ Scenario } & \multicolumn{2}{|c|}{$\alpha=0.7$} & \multicolumn{2}{|c|}{$\alpha=0.8$} & \multicolumn{2}{|c|}{$\alpha=0.9$} \\
\hline & $c$ & Cost & $c$ & Cost & $c$ & Cost \\
\hline Scenario 1 & 0.30 & 2,513 & 0.19 & 2,524 & 0.07 & 2,581 \\
\hline Scenario 2 & 0.29 & 2,505 & 0.18 & 2,513 & 0.07 & 2,549 \\
\hline
\end{tabular}

Table 2: Combinations of $(c, \alpha)$ that satisfy the permanence criterion for different correlation levels of the land returns: $\rho_{I, A}=0.9, \rho_{I A}=0.5$ and $\rho_{I, A}=0.0$. In Scenario $1 \sigma_{I}=0.01$ and $\sigma_{A}=0.015$, whereas in scenario $2 \sigma_{I}=0.025$ and $\sigma_{A}=0.015$. The remaining model parameters are as specified in Table 1 . The unit for the policy costs is $\$ / h a$ over a 30-year period.

\section{Policy scenarios: REDD payments to landowners in Parana State, Brazil}

This section applies the model presented in Section 2 to real-world REDD policy scenarios. Participants in our hypothetical payment scheme are landowners from Parana State in Brazil who grow soybean for commercial purposes. For these landowners, the opportunity cost of keeping land in forest determines the minimum level at which their participation can be secured. In constructing the return processes from two alternative land uses, forest and agriculture, recall that the former is based on a payment scheme with fixed and variable components. The model parameters of the variable component is calibrated using data extracted from two price indices, respectively, the European Union Emission Trading System (ETS) and the Chicago Board of Trade (CBOT) Soybean May Futures index. We calibrate the parameters in order to elicit the most cost-effective payment scheme while 
also satisfying the permanence criterion.

\subsection{Calibration of model parameters}

To begin, we construct the $I(t)$ return process by first indexing the forest payment to the log returns of transferable permits exchanged under the EU ETS. We estimate the amount of carbon dioxide that would be emitted in case of deforestation on a single hectare of forest land and multiply it by the historical time-series of the permit price. Formally, this corresponds to:

$$
I(t)=C O_{2}^{H a} \cdot p_{C O_{2}}(t)-C M
$$

where $\mathrm{CO}_{2}^{\mathrm{Ha}}$ is the amount (in tons) of carbon dioxide per hectare, $p_{\mathrm{CO}_{2}}(t)$ is the price of carbon permits at time $t$, and $C M$ represents all costs such as fixed management and transaction costs. In particular, $p_{\mathrm{CO}_{2}}(t)$ corresponds to the price of European Union Allowances Units (EUA) futures traded on the European Climate Exchange. This is the most liquid market for permits. We use quoted futures with maturity December 2010, from March 31, 2006 to June 2010. Prices are converted into US\$. The index is first constructed using Equation (13). Next, the parameters of Equation (1) are calibrated via maximum likelihood and are reported in Table 3 (a similar calibration is undertaken for the CBOT May futures and for the agricultural returns. Note that Equation (2) is used for the latter). For the amount of carbon per ha (the parameter $\mathrm{CO}_{2}^{\mathrm{Ha}}$ ), we rely on the values and methodology cited in Busch et al. (2009). For management and transaction costs, the default value in Busch et al. (2009) of US\$ 4.20 per hectare per year (2008 figures) is used. The values of $\mathrm{CO}_{2}^{\mathrm{Ha}}$ and $C M$ are reported in Table 4 , as are conversion costs. ${ }^{13}$ We assume the same starting value for the emissions index as for the agricultural index.

Farmers in Parana use the CBOT May futures of soybean as an indicator for the price of soybean at harvesting and selling time. It thus forms their expectations of what they might receive for their crops in a few months time. Harvesting time in Parana occurs between late February and early April. Most of the sales are then made within three months after harvest. ${ }^{14}$ For the second index, we consider the time series of the CBOT Soybean May

\footnotetext{
${ }^{13}$ Land conversion costs include profits (from timber harvesting) and costs (e.g. timber extraction costs, taxes, land costs and clearing and farm establishment costs). For the profit from timber harvesting, we assume an average timber rent of US\$ 261 per hectare (Busch et al., 2009). Other research suggests a wide range in estimates of timber returns. For example, Boerner and Wunder (2008) find total net returns from timber extraction in Mato Grosso to range from US\$ 109 to 734 per ha.

${ }^{14}$ In the state of Parana in Brazil, farmers usually plant corn as a second yearly crop after the soy is harvested. We simplify in order to keep everything tractable and assume that there are two soy harvests
} 


\begin{tabular}{cccccc}
\hline \multicolumn{2}{c}{ EUA } & \multicolumn{2}{c}{ CBOT } & \multicolumn{2}{c}{ CEPEA } \\
\hline$\mu_{E I}$ & 0 & $\mu_{C I}$ & 0 & $\mu_{A}$ & 0 \\
$\sigma_{E I}^{2}$ & 0.029 & $\sigma_{C I}^{2}$ & 0.017 & $\sigma_{A}^{2}$ & 0.015 \\
\hline
\end{tabular}

Table 3: Calibrated parameters for (i) the emissions index (European Union Units Allowances, EUA) futures contracts from March 31, 2006 to 30 June, 2010; (ii) the agricultural index (CBOT Soybean Index) from March 31, 2006 to March 31, 2011; and (iii) the constructed index for soybean produced in Parana state (CEPEA) from March 31, 2006 to August 31, 2010. The estimated unconditional correlation value between the EUA prices and the prices of Brazilian soybean is approximately zero, therefore in this case $\rho_{E A}=0.0$. The estimated unconditional correlation value between the CBOT index and the prices of Brazilian soybean is $\rho_{I A}=0.93$.

futures from March 31, 2006 to March 25, 2011. Finally, for the farmers' agricultural return process $A(t)$, we use the CEPEA/ESALQ index for soybean produced in Parana state, Brazil. The prices are quoted in US $\$$ per $60 \mathrm{~kg}$ bag. We assume an average yield of 105 bushels per hectare soybean. With average production costs of US $\$ 775$ per hectare and transportation costs of US $\$ 0.5$ per bushel, the return process $A(t)$ corresponds to net profit of soybean production per hectare. The remaining parameters used are in Table 4.

The starting values of the REDD payment indices are made equivalent to the landowner's alternative returns. Equating these initial values also allows us to focus more on the dependency structure between returns and the volatility of returns.

\subsection{Discussion}

With the return processes calibrated, we solve the optimal switching problem numerically and determine the pairs $(c, \alpha)$ that satisfy a permanence criterion of 90 percent over 30 years. We compare the cost-effectiveness of payments made to landowners in the Brazilian state of Parana whether indexed to the carbon market price (EUA futures) in the European Union ETS, or indexed to the CBOT soybean index .

The results are shown in Table 5. The volatility of soy returns is similar to that of the landowner's alternative returns while the volatility of carbon returns has a higher level than the volatility of the alternative returns. At all levels of $\alpha$, REDD payments linked to the soy index have lower overall policy costs than payments linked to the carbon index and are hence, more cost-effective. Moreover, for both payment indices, the most cost-effective policy is one with a relatively higher fixed and a lower variable payment component. When

per year. This does not significantly alter our results. 


\begin{tabular}{cc}
\hline Description & Value \\
\hline Avg. yield (soybean) & 105 bushels $/$ ha \\
Cost of production & US $\$ 5-5.50$ per bushel \\
Cost of production & US $\$ 775$ per ha \\
Transportation costs & US $\$ 0.50$ per bushel \\
Mean soybean price & US $\$ 11$ per bushel \\
\hline Management costs per ha, CM & US $\$ 4.20$ \\
Above and below ground biomass carbon & 106 tons $\mathrm{C} /$ ha \\
Soil carbon & 96.67 tons $\mathrm{C} /$ ha \\
Total Carbon & 116 tons $\mathrm{C} /$ ha \\
Total CO C $_{2}$ (factor 3.67$)$ & 426 tons $\mathrm{CO} / \mathrm{ha}$ \\
\hline$C C_{F A}$ & $370-620 \mathrm{US} \$ /$ ha \\
Profits from lumber/timber harvesting & $30 \%$ of conversion costs \\
\hline
\end{tabular}

Table 4: Parameters used for the construction of the return forest processes $I(t)$, the agriculture return process $A(t)$, and for the simulation of the returns processes. Data on soy prices are from Escola Superior de Agricultura Luiz de Queiroz (ESALQ) and the remaining data are from Conservation International and from Soybean and Corn Advisor.

payments are strongly indexed to carbon prices (i.e. high $\alpha$ ), scheme costs go up to towards US\$2,625/ha falling to US $\$ 2,423 /$ ha when payments are weakly indexed. For payments tied to the soybean index, scheme costs are US\$2,421-2,483/ha depending on the level of $\alpha$.

\begin{tabular}{|c|c|c|c|c|c|c|c|c|c|c|}
\hline \multirow[t]{2}{*}{ Index } & \multicolumn{2}{|c|}{$\alpha=0.5$} & \multicolumn{2}{|c|}{$\alpha=0.6$} & \multicolumn{2}{|c|}{$\alpha=0.7$} & \multicolumn{2}{|c|}{$\alpha=0.8$} & \multicolumn{2}{|c|}{$\alpha=0.9$} \\
\hline & $c$ & Cost & $c$ & Cost & $c$ & Cost & $c$ & Cost & $c$ & Cost \\
\hline & 5 & 4 & 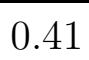 & 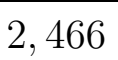 & 8 & 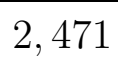 & & 2,5 & r & 2,62 \\
\hline Soy & 0.52 & 2,421 & 0.40 & 2,446 & 0.29 & 2,461 & 0.17 & 2,467 & 0.05 & 2,483 \\
\hline
\end{tabular}

Table 5: Combinations of $(c, \alpha)$ that satisfy the permanence criterion for a carbon and a soy index. The unit of costs is in $\$ /$ ha over a 30 -year period.

In summary, indexed payments to the landowner are lower when tied to the soybean index compared to the carbon index. In light of indexing REDD contracts to the carbon market price this result has important policy implications. It indicates that scheme costs could be reduced by around 5-10 percent while maintaining the same level of permanence if payments are instead linked to a relevant agricultural commodity price index. This cost saving assumes a carbon service buyer would choose to target REDD in areas of high 
deforestation risk that also have high agricultural value. He may, of course, decide to target areas of high deforestation risk but where agriculture brings much lower returns. In this case, payments indexed to agricultural commodities of lower value will be even cheaper than ones indexed to soybean, relative to payments indexed to carbon prices.

\section{Conclusions and implications for REDD policy de- sign}

This paper investigates the implications of landowners' option values in decisions over how to allocate land use with a focus on land-use change between forest and agriculture. Irreversible sunk costs along with uncertainties over the returns from future land use are modeled in order to provide insights into the design of payment schemes for Reducing Emissions from Deforestation and Degradation (REDD). Given that REDD will not represent a permanent change in the cumulative flux of carbon dioxide to the atmosphere, scheme design is motivated by a need to secure forest carbon sinks over time while remaining relatively cost-effective. Since perfect permanence is clearly impossible to attain, the aim is to minimise the cost of the policy with a given level of risk of deforestation as a result of landowners' changing opportunity costs.

We develop a model of optimal land-use change under stochastic returns in which a variable payment component based on an observable price index is introduced alongside a constant, fixed component. The latter are the usual vehicle for many PES schemes in

operation around the world. Variable payments based on carbon prices could feature if REDD is integrated into a carbon offset market. A variable payment component based on an agricultural commodity index is an innovation that has been proposed in the literature but has not been implemented in actual payment schemes nor has it been thoroughly explored in previous research. An innovation of our framework is to establish a probabilistic permanence criterion in all of our simulations. Thus, for a given hectare of forestland we derive the payment scheme that ensures the land remains in forest over a given time horizon with a probability not lower than a specified level. We set the criterion at a probability of 90 percent with a time horizon of 30 years.

The relative cost-effectiveness of different payment schemes is examined in Sections 2 and 3. Two different scenarios for the dependency structure between the two competing land returns are considered: uncorrelated and positively correlated. Our results suggest 
that the higher the correlation between the returns from the indexed component of the payment and the returns from the alternative land use, the lower the cost of the policy overall. Therefore, in choosing between indexing REDD payments to prices in a carbon market or prices in a relevant agricultural index, the policy regulator should opt for the latter if aiming for cost-effectiveness when the alternative land use is agriculture. Yet, in reality, REDD buyers might prefer to tie payments to the EUA index since carbon market risks are ones they better understand and can manage rather than to an agricultural commodity index that they may understand less well. Furthermore, the greater the volatility of the returns, the higher the upside potential profits. These results are consistent with the standard literature on optimal land-use change: when conversion costs from forest to agriculture are sunk and the returns from alternative land uses are potentially less profitable, the land owner delays land-use change. This is what we observe when REDD payments are indexed to a relatively volatile carbon price. It should be noted, however, that when the competing returns are strongly correlated it is not unreasonable to expect their volatility levels to be of a similar magnitude.

In our framework, we compare the costs of different payment schemes that combine fixed and variable components. Two remarks are in order. First, it is not yet clear that landowner-scale incentive payment schemes will be a significant feature of a future, international-level REDD scheme. While payments may play a role in project-scale pilot activities, perhaps in national-level schemes, other policy instruments such as protected areas will come into play at least in the short-term. Second, when the variable component is reduced, with the REDD payment moving towards an exclusively fixed transfer, we are approximating the certainty equivalent. In this setup, the certainty equivalent is the amount of payment that a landowner would have to receive to be indifferent between that payment and the alternative (risky), agricultural returns.

While these results are unsurprising in a model of optimal land-use change with riskneutral agents, we note that they may create some confusion among practitioners working with PES schemes and other policies for REDD. Previous research that examined informational differences between policies appeared to show that indexed payments might be more cost-effective than fixed ones. For example, using a principal-agent framework with asymmetric information on the agent's opportunity cost, MacKenzie et al. (2011) show that when the landowner's opportunity cost is observable the principal's rent and the level of carbon sequestration from the contract are always larger under indexing, i.e. compared to the case where it is unobservable and indexing is not possible. Our modeling frame- 
work operates in a similar information setting to that of first-best contracts and hence, does not explicitly consider informational rents. Namely, we show that information about a landowner's opportunity cost is valuable only if alternative returns are correlated to a relevant index. If they are uncorrelated a policy weighted towards indexed payments is relatively more expensive than one with more weight on a fixed transfer, i.e. there is an informational difference between the two payment schemes.

Finally, we note two further issues and ideas for future research. First, landowners' opportunity costs and, more generally, their land-use decisions are unlikely to be driven by a single factor such as the returns from alternative land uses. Second, where these schemes are used a variable payment component may be more costly to implement than a fixed component alone. This could be subject to future, empirical research.

\section{References}

Angelsen, A. (2010). What policies are effective to reduce deforestation while enhancing production? PNAS, 107(46):19639-19644.

Angelsen, A. and Kaimowitz, D., editors (2001). Agricultural Technologies and Tropical Deforestation. Center for International Forestry Research, Jakarta, Indonesia.

Behan, J., McQuinn, K., and Roche, M. (2006). Rural land use: Traditional agriculture or forestry? Land Economics, 82(1):112-123.

Benítez, P., Kuosmanen, T., Olschewski, R., and van Kooten, G. (2006). Conservation payments under risk: a stochastic dominance approach. American Journal of Agricultural Economics, 88(1):1-15.

Boerner, J. and Wunder, S. (2008). Paying for avoided deforestation in the Brazilian Amazon: from cost assessment to scheme design. International Forestry Review, 10(3):496511.

Bulte, E., van Soest, D., Van Kooten, G., and Schipper, R. (2002). Forest conservation in Costa Rica when nonuse benefits are uncertain but rising. American Journal of Agricultural Economics, 84(1):150-160.

Busch, J., Strassburg, B., Cattaneo, A., Lubowski, R., Boltz, F., Ashton, R., Bruner, A., Creed, A., Obersteiner, M., and Rice, R. (2009). Collaborative modeling initiative 
on REDD economics. In IOP Conference Series: Earth and Environmental Science, volume 6 .

Butler, R., Koh, L., and Ghazoul, J. (2009). REDD in the red: palm oil could undermine carbon payment schemes. Conservation Letters, 2(2):67-73.

Chomitz, K. and Thomas, T. (2001). Geographic patterns of land use and land intensity in the Brazilian Amazon. Policy Research Working Paper Series 2687, The World Bank.

Dangl, T. and Wirl, F. (2004). Investment under uncertainty: calculating the value function when the Bellman equation cannot be solved analytically. Journal of Economic Dynamics and Control, 28(7):1437-1460.

Dixit, A. (1989). Entry and exit decisions under uncertainty. Journal of Political Economy, 97(3):620-638.

Dixit, A. K. and Pindyck, R. S. (1994). Investment Under Uncertainty. Princeton University Press, Princeton, New Jersey.

Dutschke, M. and Angelsen, A. (2008). How do we ensure permanence and assign liability?, volume Moving Ahead with REDD: Issues, Options and Implications., pages 77-86. Center for International Forestry Research (CIFOR), Bogor, Indonesia.

Dutschke, M. and Wong, J. (2003). Can permanence be insured? consideration of some technical and practical issues of insuring carbon credits from afforestation and reforestation. HWWA Discussion Paper No. 26270.

Eliasch, J. (2008). Climate Change: Financing Global Forests. Earthscan, London.

Engel, S., Pagiola, S., and Wunder, S. (2008). Designing payments for environmental services in theory and practice: An overview of the issues. Ecological Economics, 65(4):663674 .

Fearnside, P. M. (2001). Soybean cultivation as a threat to the environment in Brazil . Environmental Conservation, 28:23-38.

Ferraro, P. J. and Kiss, A. (2002). Direct payments for biodiversity conservation. Science, 298:1718-1719. 
Ferraro, P. J. and Simpson, R. D. (2002). The cost-effectiveness of conservation performance payments. Land Economics, 78(3):339-353.

Gregersen, H., Lakany, H. E., Karsenty, A., and White, A. (2010). Does the opportunity cost approach indicate the real cost of REDD+. Technical report, Right and Resources Initiative, Washington, DC, US.

Grieg-Gran, M. (2009). Costs of avoided deforestation as a climate change mitigation option. In Palmer, C. and Engel, S., editors, Avoided Deforestation: Prospects for Mitigating Climate Change, pages 11-38. Routledge, Abingdon, UK.

Groom, B. and Palmer, C. (2010). Cost-effective provision of environmental services: the role of relaxing market constraints. Environment and Development Economics, $15(2): 219-240$.

Guthrie, G. and Kumareswaran, D. (2009). Carbon subsidies, taxes and optimal forest management. Environmental and Resource Economics, 43(2):275-293.

Isik, M. and Yang, W. (2004). An analysis of the effects of uncertainty and irreversibility on farmer participation in the conservation reserve program. Journal of Agricultural and Resource Economics, 29(2):242-259.

Lecocq, F. and Chomitz, K. (2001). Optimal use of carbon sequestration in a global climate change strategy : is there a wooden bridge to a clean energy future ? Policy Research Working Paper Series 2635, The World Bank.

MacKenzie, I. A., Ohndorf, M., and Palmer, C. (2011). Enforcement-proof contracts with moral hazard in precaution: ensuring 'permanence' in carbon sequestration. Oxford Economic Papers - forthcoming.

McDonald, R. and Siegel, D. (1986). The value of waiting to invest. The Quarterly Journal of Economics, 101(4):707-728.

Mehta, A., S. C. and Capoor, K. (2003). Contracting for carbon. Environmental Finance, pages $28-29$.

Miranda, M. J. and Fackler, P. L. (2002). Applied Computational Economics and Finance. MIT Press. 
Muller, J. and Albers, H. (2004). Enforcement, payments, and development projects near protected areas: how the market setting determines what works where. Resource and Energy Economics, 26(2):185-204.

Nepstad, D., Soares-Filho, B., Merry, F., Moutinho, P., Rodrigues, H., Schwartzman, S., O., A., and S., R. (2007). The costs and benefits of reducing carbon emissions from deforestation and forest degradation in the Brazilian Amazon. Woods Hole Research Center.

Palmer, C. (2011). Property rights and liability for deforestation under REDD+: implications for 'permanence' in policy design. Ecological Economics, 70(4):571-576.

Palmer, C. and Engel, S. (2009). Avoided Deforestation: Prospects for Mitigating Climate Change. Routledge, Abingdon, UK.

Palmer, C. and Silber, T. (2012). Trade-offs between carbon sequestration and poverty alleviation in community-based land use systems: Preliminary evidence from Mozambique. Land use policy, 29(1):83-93.

Pindyck, R. S. (1988). Irreversible investment, capacity choice, and the value of the firm. American Economic Review, 78(5):969-985.

Pindyck, R. S. (1991). Irreversibility, uncertainty, and investment. Journal of Economic Literature, 29(3):1110-1148.

Schatzki, T. (2003). Options, uncertainty and sunk costs: an empirical analysis of land use change. Journal of environmental economics and management, 46(1):86-105.

Stern, N. (2007). The Economics of Climate Change. The Stern Review. Cambridge University Press, Cambridge - UK.

Streck, C. (2005). World bank carbon finance business: Contracts and emission reductions purchase transactions. In Freestone, D. and Streck, C., editors, Legal aspects of implementing the Kyoto Protocol mechanisms: making Kyoto work. Oxford University Press.

UNFCCC (2010). Report of the conference of the parties on its sixteenth session, held in cancun. Draft decision-/cp.16, (United Nations Framework Convention on Climate Change). 
van der Werf, G. R., Morton, D. C., DeFries, R. S., Olivier, J. G. J., Kasibhatla, P. S., Jackson, R. B., Collatz, G. J., and Randerson, J. T. (2009). $\mathrm{CO}_{2}$ emissions from forest loss . Nature Geoscience, 2:737-738.

Watson, R., Noble, I., Bolin, B., Ravindranath, N., Verardo, D., and Dokken, D. (2000). Land-use Change, and Forestry: A Special Report of the Intergovernmental Panel on Climate Change. Cambridge University Press, Cambridge, UK.

Wiemers, E. and Behan, J. (2004). Farm forestry investment in Ireland under uncertainty. The Economic and Social Review, 35(3):305-320. 